\title{
Educational Expansion and Homogamy. An Analysis of the Consequences of Educational Upgrading for Assortative Mating in Switzerland
}

\author{
Rolf Becker* and Ben Jann**
}

Abstract: We analyze the changing relationship between education and assortative mating over the course of educational expansion in Switzerland between 1970 and 2000. The overall rate of educationally homogamous partnerships has remained rather stable, while partnerlessness increased and became less educationally selective. An analysis taking the opportunity structure into account reveals that the inclination toward educationally homogamous partnerships is most pronounced in lower educational groups, but that the differences between educational groups decreased over time.

Keywords: educational expansion, educational homogamy, census, social stratification

\section{Bildungsexpansion und Homogamie. Eine Analyse der Auswirkungen von Höherqualifikation auf die Partnerwahl in der Schweiz}

Zusammenfassung: Für die Schweiz wird mit Zensusdaten untersucht, wie sich der Zusammenhang zwischen Bildung und Partnerwahl zwischen 1970 und 2000 im Zuge der Bildungsexpansion gewandelt hat. Die Rate bildungshomogamer Partnerschaften blieb insgesamt relativ stabil, während Partnerlosigkeit zunahm und sich zwischen den Bildungsgruppen tendenziell anglich. Eine um die Gelegenheitsstruktur bereinigte Analyse zeigt, dass die Neigung für homogame Partnerschaften in den unteren Bildungsgruppen am stärksten ausgeprägt ist, die Unterschiede zwischen den Bildungsgruppen jedoch über die Zeit abgenommen haben.

Schlüsselwörter: Bildungsexpansion, Bildungshomogamie, Zensus, soziale Ungleichheit

\section{Expansion du système de formation et homogamie - analyse de l'impact des qualifications supérieures sur le choix du partenaire en Suisse}

Résumé: Cet article analyse l'évolution du lien entre formation et choix du partenaire entre 1970 et 2000 au cours de l'expansion du système de formation en Suisse. Le taux de partenariats caractérisés par une homogamie de formation est resté relativement stable dans l'ensemble, tandis que le taux de personnes vivant sans partenaire a augmenté et est devenu moins dépendant du niveau de formation. Une analyse tenant compte des opportunités différentielles révèle que le penchant pour l'homogamie est plus fort dans les groupes au niveau de formation inférieur, mais que l'écart entre les groupes de formation a diminué au cours des années.

Mots-clés: expansion du système de formation, homogamie de formation, recensement de la population, inégalité sociale

\footnotetext{
* Department of Sociology of Education, University of Bern, CH-3012 Bern, rolf.becker@edu.unibe.ch.

** Institute of Sociology, University of Bern, CH-3012 Bern, ben.jann@soz.unibe.ch.
} 
Over the course of the educational expansion since the middle of the 20th century, many societies experienced far-reaching changes in social structure (Hadjar and Becker 2009), particularly with respect to educational behavior (Müller 1998). Across cohorts, increased participation in continuing and higher education and remaining longer in the educational system led both to a gradually increasing level of qualification in the population (Breen et al. 2010, 2009) and to different life choices in the course of extended educational opportunities (Mayer and Blossfeld 1990). These developments included postponing marriage and family formation (Blossfeld and Huninik 1991; Diekmann 1990), changing opportunities in the partnership and marriage market (Blossfeld 2009; Schwartz and Mare 2012), increased partnerlessness and childlessness (Konietzka and Kreyenfeld 2014; Huinink 2000), and socio-structural changes in marital stability (Diekmann and Schmidheiny 2001; Klein and Kopp 1999). Educational expansion has impacted the frequency, structure, and timing of these life events (Mayer 1996).

Switzerland may be a special case in terms of the expected and unexpected consequences of educational expansion for demographic processes. This is due to peculiarities in its process of educational expansion (Becker and Zangger 2013) and its specific social structures and inequalities (Jann and Combet 2012). Educational expansion was slower in Switzerland than in other Western European countries (Hadjar and Berger 2010; Pfeffer 2008; Buchmann et al. 2007; Blossfeld and Shavit 1993). As a result of educational expansion, the social inequality of educational opportunities was marginally reduced in Switzerland (Becker and Zangger 2013) compared with other Western European countries (Breen et al. 2010 2009), and the intergenerational transmission of educational attainment and class decreased slightly (Jann and Combet 2012). Nevertheless, largely, educational reproduction (Zangger and Becker 2016) and social mobility have been stable (Falcon 2016). Furthermore, although female labor force participation increased over the course of the educational expansion and the tertiarization of the occupational and economic structures, a gendered division of labor continues to prevail in private households, a phenomenon which has been described as "modernized traditionalism" (Levy 2013, 236).

In contrast, there are no reliable findings for Switzerland as to whether educational expansion was associated with an increased importance of the educational system in the partnership and marriage market, as was found for other Western European countries (Schwartz and Mare 2012; Blossfeld 2009; Blossfeld and Timm 2003). There are a few cross-sectional studies available for Switzerland, which report a distinctively pronounced educational homogamy (Katrnak et al. 2012; Domanski 
and Przybysz 2007; Smits et al. 1998). ${ }^{1}$ However, these analyses consider neither the changes in marriage patterns nor the consequences of educational expansion for the choice of a partner or for marriage behavior in the Swiss population.

Changes in partnership search and marriage opportunities can be expected, because women were disproportionately impacted by the educational expansion. In terms of the acquisition of higher education, women have not only caught up with men (Zangger and Becker 2016); they have overtaken them (Imdorf and Hupka-Brunner 2015; Becker et al. 2013). Given the sporadic nature of these analyses for Switzerland, it is unclear whether the gender-specific educational upgrading in general (and the reversal of gender-specific educational chances and the changed work behavior of women on the job market in particular) have led to changes in education-specific marriage patterns, for example by increasing the bargaining power of women (Schwartz and Han 2014). While in the past parents invested in the education of their daughters to prepare them for the marriage market (Breen et al. 2010), following educational expansion it might be that women invest more in their education to further their careers (Imdorf and Hupka-Brunner 2015, 261), to foster economic independence in case of separation, divorce, or widowhood, to optimize the compatibility of family and work (Levy 2013) or, more generally, to shape their lives independently of a partner (Becker 2014; DiPrete and Buchmann 2013).

Answers to these questions are interesting from a socio-structural point of view, because the extent of educational homogamy and the structural change of educational heterogamy in the course of educational expansion provide additional information about the reproduction of social inequality (Blossfeld 2009; Mare 1991). Such indicators can be interpreted as evidence of the openness of a society's structure (Blau et al. 1982). ${ }^{2}$ In the same way as the educational expansion occurred through birth cohorts, better educated women and men may be the cultural carriers of the changes in partnership markets and the social structure of education-specific marriages, and (concomitantly) of changes in the openness of societies. Since particularly women - despite the continued horizontal segregation of educational opportunities and benefits by gender (Imdorf and Hupka-Brunner 2015) - have profited from the educational expansion in Switzerland, the rate of educational homogamy probably increased (more for women than for men) because of the shift of their negotiating power in their partnerships and in the marriage market (Diekmann 1990). Tertiary vocational and especially university education may be an important asset on a part-

1 "Educational homogamy" or "homogamy" refers to the fact that individuals with a certain educational level marry partners with the same educational level. The choice of a partner with a different educational level is called "heterogamy." "Hypergamy" is present if a woman marries a man with a higher educational level, while "hypogamy" means that a woman marries a man with a lower educational level.

2 They can also demonstrate the socio-structural changes in life courses in general, and in familydemographic processes such as partnership, marriage, separation, divorce, or family formation in particular. This allows one to reconstruct the change in the social structures in the sense of a differentiated social history of societies. 
nership market that is structured increasingly by the educational system. However, whether the educational expansion in Switzerland led to a social closure or opening of the partnership and marriage markets is a question that has yet to be answered empirically (see Blossfeld 2009).

The objective of the present contribution is therefore to describe the changes in educational homogamy across birth cohorts over the course of the educational expansion in the second half of the $20^{\text {th }}$ century. The socio-historical process of educational expansion and changing educational homogamy is illustrated using a cohort design based on data from the Swiss censuses of 1970, 1980, 1990 and 2000. Indirectly, the idea is to ascertain whether the educational system has gained in importance as a partnership market in Switzerland, and to identify the extent to which educational upgrading led to social closure or opening in assortative mating. Finally, we are interested in whether women disproportionately profited from this development. Findings on the latter question are sociologically relevant because they provide empirical evidence for changes in the bargaining power of the sexes in the partnership and marriage markets.

The article is structured as follows: The second section focuses on the state of research and the theoretical background; the third contains a description of the data and variables; the fourth covers the empirical findings; and the fifth includes a summary and concluding discussion.

\section{State of research and theoretical background}

Sociological research regarding the relationship between education and the choice of a partner, between educational expansion and marital age, and between the educational system and the partnership market, has a long tradition (Schwartz 2013; Blossfeld 2009; Kalmijn 1998; Blau 1977). Findings vary greatly, depending on the data and the design of the analyses, as well as on the observed countries and historical periods. For example, older international comparative studies document a close connection between the educational level and the choice of a partner (Ultee and Luijx 1990; Kalmijn 1991), and the gender-specific differences of this connection (Schwartz and Han 2014; Schwartz and Mare 2012). In this literature, educational homogamy is emphasized repeatedly as a structural characteristic of modern societies. With respect to heterogamy, typical findings are that women usually marry men with the next higher educational level, while men prefer women with a lower education (Wirth 1996). Men with less education tend to remain single, and women are seldom partnered with men of less education (Lichter et al. 1995; Blossfeld and Timm 1997). Seen in this way, the partnership and marriage markets are characterized by a social, cultural, and economic closure based on the educational success and educational attainment of the potential partners. The attractiveness of people who 
are successful in the educational system also correlates with their expected economic success and future lifestyle (Arum et al. 2008).

Educational expansion, according to the available evidence (Blossfeld 2009), shifted the average age at first marriage because of the longer time spent in the educational system (structural effect in terms of a delayed timing of the first marriage) ${ }^{3}$ and also affected the prevalence of educational homogamy (level effect in terms of normative preferences for a partner with same education). ${ }^{4}$ The findings with respect to the historical trends of educational homogamy, however, are inconsistent, and the conclusions are mixed (Schwartz 2013). On the one hand, the findings show long trends of modernization with declining homogamy rates and an increased opening of social structures (Ultee and Luijx 1990). On the other hand, for individual countries - for instance, the United States or West Germany - increasing rates of homogamy have been found, particularly at higher educational levels (Schwartz and Mare 2005). Furthermore, different developments are reported for the same country, depending on the cross-sectional trend data or longitudinal data in use. While Blossfeld (2009), Timm (2006), and Blossfeld and Timm (1997) report a rising educational homogamy for successive birth cohorts in Germany based on life course data, Wirth (1996) finds relatively constant rates of educational homogamy over time by means of comparative-static micro-census data. Klein (2000) also concludes that the homogamy rates decline if both sexes profit from educational expansion, specifically in West Germany (see Becker 2014). Domanski and Przybysz (2007) find high rates of educational homogamy in Switzerland based on crosssectional data from the European Social Survey for 2004-2005, but do not say whether this is a consequence of educational expansion. Switzerland appears to be a country with low mobility rates as well as a limited openness and opening of the class structure, even in the recent past (Falcon 2016; Jann and Combet 2012).

The postponement of marital age caused by the educational expansion, and/or the longer period spent in the educational system, is sociologically interesting because marital age is a key sociodemographic factor that is interrelated with various other social and demographic variables (as argued, for instance, by Diekmann 1990). For example, marital age correlates with birth rate and affects the gap between generations, the risk of divorce, the date when the children move out of the parents' home, career behavior, the income distribution, and the distribution of household sizes. Marital age also impacts on the educational system, the housing market, the job market, and government welfare systems. In general, the shift of partnership age and marriage age has far-reaching effects on various events and transitions in the life course of adults and their children (Arum et al. 2008: 108).

4 According to Swiss official statistics, between 1950 and the beginning of the 1970s the average marital age fell from 26 to 24 years among women and from 28 to 26.5 years among men, but then increased until 2014 to 29 years for women and 32 years for men. Although the actual change is overestimated, using period rather than cohort estimates (Huinink 1995), this development can be interpreted as a consequence of educational expansion. Considered from a life history perspective, however, the shift in marital age also has consequences for the measurement and interpretation of changes in educational homogamy. One could argue that changes in homogamy could best be observed by comparing people at the time when they leave the educational system, not necessarily by comparing them at the same age (Timm 2006; Blossfeld and Timm 2003; 1997; Schwartz and Mare 2012). 
The high intergenerational reproduction of education (that is, the low educational mobility between the generations) may be one reason why the rate of educational homogamy is very pronounced, for example when compared to 28 other countries analyzed by Katrnak et al. (2012). Furthermore, the women's declining hyper- and hypogamy rates are accompanied by a rising stability of educationally homogamous marriages, while heterogamous marriages (particularly if the woman has the higher education) are unstable (Schwartz and Han 2014). This finding for the USA is confirmed for Switzerland by Diekmann and Schmidheiny (2001).

Empirical studies agree that, due to educational expansion, the educational system - compared with the workplace, the neighborhood, family networks, or clubs (Kalmijn and Flap 2001) - has become the most important marriage market (Blossfeld and Timm 2003; Kalmijn 1991, 791). Its importance extends not only to direct opportunity structures (Mare 1991), according to which potential spouses meet in the classroom, but also to indirectly selective opportunities through extracurricular social areas, such as social networks, neighborhoods, and workplaces. The patterns of educational homogamy, however, are determined primarily by the vertical dimension of the educational levels (Mare 1991, 15-16) such that the educational system structurally and normatively organizes educationally segregated partnership markets and homogamous partner choice. Educational expansion has significantly increased the chances that partners of a similar age and education find one another in the educational system or on other markets after completing their education. Above all, the changing economic role of women (Blossfeld 2009) makes their educational level and career ever more important for finding a "match" on the marriage markets, both within and outside the educational system. Nevertheless, as mentioned above, this "structural effect" operates alongside a "level effect" (Blossfeld and Huinink 1991), according to which homogamy norms still have considerable relevance for partner choice and marriage patterns (Huinink 2000, 217). Equally important is the norm in most capitalist countries to marry and establish a family only after having completed education. These norms did not become invalid due to the increase in the quality of women's human capital investments (Blossfeld 2009).

Nielsen and Svarer (2009), for instance, argue that values (e.g. with respect to the qualifications of the children, the stability of marriage, and the labor force participation of women), norms (e.g. that marriage should only occur after the completion of education) and preferences for educational homogamy (e.g. when educationally similar people appear more attractive) are shaped by education (cf. also Kalmijn 1991, 790). In addition, the non-random choice of partner due to the preference and systematic search for a similar partner (for example, a partner of the same educational level) is reinforced by the opportunities for meeting such a partner in the educational system (matching hypothesis). At the same time, the educational system offers an arena for competition for the most attractive partners, who, as a minimum, have the same educational level (competition hypothesis) (Schwartz 2013; 
Klein 2000). In both cases, homogamy will be the predominant resulting partnership if the education of the sexes is distributed evenly, if better educated economically active women do not forgo a relationship because they see no additional benefit in the traditional division of labor in the private household, and if those wanting to get married do not suspect that there are better options left among the "singles" (Blossfeld and Timm 1997). In the case of an uneven educational distribution, differences become more likely, but partnerships will still form among those with relatively close educational levels. Furthermore, differences are strengthened by the fact that men typically marry at a somewhat older age than women. Coupled with the postponement of marriage until after completion of education, this means that the marriage market can become increasingly difficult for highly educated women across their life course (Huinink 2000).

This means that the educational expansion leads to a change in the sociostructural conditions mentioned by Blau (1977), according to which, apart from the age distribution and the sex ratio in consecutive birth cohorts, the educational distribution of marriageable women and men (which changes over time) affects the chance of meeting and getting to know a potential partner with the preferred characteristics. The educational expansion thus shapes the way in which individual decision-making takes place by systematically and arithmetically changing the opportunities and restrictions on the societal marriage market. Therefore, due to structurally conditioned social segregation in the marriage market, the educational expansion - apart from the normative rules and individual preferences embedded into the opportunity structures - probably also has a direct effect on behavior regarding partner choice and marriage patterns. With the changes in gender-specific educational distributions and benefits, ongoing in Switzerland and a direct consequence of the educational expansion, the traditional education gradient between marriage partners (i.e., the man having a higher educational level than the woman) will probably decline in the succession of the birth cohorts. With the rising number of better educated women, homogamous partnerships become more likely if the choice of a partner and the demands on a partnership are structured by similarities in the characteristics of the partners (Klein 2000). In this process, as demonstrated by significant empirical evidence (Blossfeld 2009), better educated women, depending on the options on the marriage market, would often rather remain single than choose a less educated man, while less educated men without potential partners generally have the lowest chances on the partnership and marriage market. In the course of the educational expansion, therefore, partnerlessness should be particularly observable among these men.

To summarize: education is, regarding the choice of a partner and marriage, an indicator for sociocultural preferences and socioeconomic success. Concerning cultural preferences, Kalmijn $(1998,412)$ concludes that the competition between men and women with the same educational level has intensified over the course 
of the educational expansion and with the increase in numbers of highly educated women. Better educated women who are more likely to be economically active and who fetch comparatively higher educational benefits on the labor market are particularly attractive for more highly educated men because of their socioeconomic resources. According to Kalmijn (1991), given the opportunity structures and the increased attractiveness of better-educated women on the marriage market, an increasing educational homogamy can be expected, especially at higher educational levels. Therefore, with continued educational expansion, a cohort differentiation of increasing educational homogamy in the younger cohorts should be observed.

Overall, the educational system is considered a very efficient marriage market (Nielsen and Svarer 2009, 1067). With the density of potential partners at different educational levels (cf. Blau et al. 1982), and based on comparatively fewer frictions than in other local marriage markets, the search costs and the uncertainties associated with the choice of partner are significantly reduced. However, one cannot simply jump to the conclusion that the increased importance of the educational system as a marriage market has replaced the strategic role of the marriage for maintaining the intergenerational status of women in the sense of the status attainment hypothesis (Smits et al. 1998) in favor of "romantic love" (general openness hypothesis according to Smits 2003, 256) (cf. Ultee and Luijkx 1990). According to a study carried out by Arum et al. (2008), well-educated women would rather marry partners with strong income potential and a higher education level, while qualified men prefer women from families with a higher status (see also Blossfeld 2009).

The social mechanisms described above should have been strengthened by the sustained educational expansion in a modern society like Switzerland. Increasing educational homogamy can be expected to intensify the social inequality of the chances on the partnership and marriage market. In contrast, it should also contribute to the reinforcement of socially unequal educational opportunities in subsequent generations of children via socially selective marriage and family formation (see Hillmert 2012; Becker 2009). For example, Hillmert (2012) shows that a large part of the intergenerational reproduction of educational attainment can be attributed to sociodemographic processes such as educationally homogamous marriage and family formation by the parents and grandparents. This could be another explanation for the rather hesitant educational expansion and moderate decline in educational inequalities across successive generations in Switzerland. 


\section{Data, variables and methodical approach}

\subsection{Database}

The empirical analyses are based on harmonized data from the Swiss census in 1970, 1980, 1990 and 2000 (see Stamm and Lamprecht 2005). ${ }^{5}$ Because of the large number of cases and the timespan, these censuses allow a differentiated analysis of the consequences of the educational expansion for the partnership patterns of women and men in different age groups. The census covers all persons and households of Swiss residents (residence is determined by the economic and civil domicile). Because data is collected on both household structures and on all household members, married couples, single people, and cohabitation can be identified, together with other characteristics, such as gender, educational level, and date of birth. It is thus possible to trace the presumed consequences of the educational expansion in Switzerland for family-demographic processes in the second half of the $20^{\text {th }}$ century.

Even though census data are cross-sectional, the dynamics of the processes of change can be illustrated by distinguishing birth cohorts. Only a comparative-static analysis of the civil statuses "married" versus "not married," or of the partnership status, is however possible. For example, no differentiation is possible between first marriage and remarriage. For a more dynamic analysis of different partnership and marriage episodes, event-history data would be required (cf. Blossfeld and Timm 1997). Despite these methodological limitations, the census data are well suited for a differentiated analysis of the relationship between educational expansion and education-specific partnership patterns across cohorts. Due to a high degree of standardization, comparability of variables, and a large number of observations, precise results on the relevant developments can be obtained. Note that all analyses below are based on complete population data. As such, we do not present confidence intervals or other measures of statistical precision.

\subsection{Analytical population}

Our analyses are limited to persons aged 25 to 64 years. ${ }^{6}$ An overview of the size of the analyzed population in the different years is given in Table A1 in the Appendix. To avoid the distorting influence of a declining tendency to marry, which is not necessarily associated with a declining likelihood to form a partnership, we record for these persons whether they live in a partnership or not, irrespective of their civil status. However, both for married persons and persons living in a consensual partnership, couples can only be identified if both partners live in the same house-

5 Replication materials for our analysis are available from https://ideas.repec.org/p/bss/wpaper/25. html.

6 We use persons, not partnerships, as the units of analysis, because those without partners must also be included. We therefore examine all persons aged 25 to 64 years to see whether a partnership was present at the time of the census and, if so, to record the relevant information about the respective partner. No age restriction is imposed when identifying the partners. 
hold. Partnerships can be formed in the census based on the recorded information on the positions of the household members within the household. In each couple household, one person is identified as the head of household and/or reference person, along with a partner. This information does not depend on whether the persons are married to each other. ${ }^{7}$ A further division into married and unmarried couples would be possible on the basis of the data, but this distinction is not applied in the analyses below because, as indicated above, we are interested in educational homogamy across all (permanent) partnerships, irrespective of civil status.

The representation of partnerships in the census data is incomplete. As indicated, partnerships between persons living in different households cannot be identified. Conversely, for certain household settings, even partnerships within a household cannot or can only partially be identified. An example is households composed of several couples. In general, in such cases only one couple is identified and the other persons are recorded as being partnerless. There might also be households in which the two persons making up the partnership do not include the reference person of the household. Such couples can be identified only if they are the parents or in-laws of the reference person. To simplify matters, we assume in such cases that a couple exists if there are exactly two parents of different gender in the household who are both married. Overall, due to a pluralization of living arrangements, it could be that partnerships within households are increasingly under-reported over time. In any case, the effect on our results should be negligible.

\subsection{Dependent and independent variables}

The main variables are the partnership status (0/1) and the highest educational attainment of the target person and its partner. As indicated above, we can only identify partnerships if both partners live in the same household; people with a stable relationship with a person outside the household are treated as single. Furthermore, following the usual conventions and considering the lack of details in the collected data, a distinction is made between the following educational levels: (1) compulsory schooling or less, (2) professional certificate at the secondary level II, (3) general education certificate at the secondary level II, (4) professional tertiary certificate and (5) academic tertiary certificate (including certificates from universities of applied sciences). ${ }^{8}$

7 One limitation is that consensual couples do not seem to have been recorded in the 1970 census, presumably because households containing a consensual couple were rare at that time. This implies that the increase in the proportion of persons without a partner was probably somewhat more pronounced between 1970 and 1980 than indicated in the results below, particularly for the younger cohorts.

8 Educational attainment is unknown for a minority of observed individuals (Table A1 in the Appendix). For the classification of the highest educational attainment, we use the harmonized variable HABGB (highest attainment gross) of Chaze (2005), which should be comparable over time for the age groups analyzed here (see also Chaze et al. 2005). Alternatively, the variable 
On the basis of a comparison of the educational levels of the two people in a partnership, a homogamy variable is also formed with the following categories: (1) The target person has a higher educational attainment than the partner; (2) both partners have the same educational attainment; (3) the target person has a lower educational attainment than the partner. For some observations, the value of the homogamy variable cannot be determined due to lack of information on the educational level for at least one of the partners (see Table A1 in the Appendix). Since in Switzerland mixed-sex partnerships are still the rule, all analyses are done separately by gender.

To isolate cohort effects, all analyses are separated by age groups, using five-year intervals (25-29-year-olds, 30-34-year-olds, etc.). By combining year of birth, partnership status, and educational level, the cohort design allows one to determine the impact of educational expansion on the choice of a partner and marriage patterns (Timm 2006; Blossfeld and Timm 1997; Diekmann 1990). Because one cannot link observations across censuses, it is not possible to follow individuals over time, considering the dynamics of the processes of partner choice and other family-demographic processes.

\subsection{Methodical approach}

In the empirical part, the changes in educational distribution as well as educational homogamy are represented over time according to the categories of the homogamy variable described above. In a further step, an attempt is made to isolate structural influences on educational homogamy, that is, influences of the changing marginal distributions due to educational expansion. For this purpose, we first calculate the observed homogamy or gross homogamy $H$ as

$$
H=\frac{\sum_{j} N_{j j}}{N}
$$

with $N$ as the size of the population (number of partnerships) and $\mathrm{N}_{j j}, j=1, \ldots$, 5 as the number of partnerships in which both partners have educational level $j$ (diagonal cells in a cross table of the educational levels of both partners). Next, we calculate the extent of random homogamy $C$ that would be expected if the partners were matched randomly (among the people who were in a partnership at that time) as

$$
C=\frac{\sum_{j} \frac{N_{j .}{ }^{*} N_{. j}}{N}}{N}
$$

HABGN (highest attainment net) could also be used. Both variables lead to virtually the same result for the analyses below. 
with $N_{j}$ as the number of target persons with educational level $j$ and $N_{. j}$ as the number of potential partners with that educational level. The educational expansion has a direct structural effect on the random homogamy $C$, because it leads to a change in the marginal distributions.

Taking into consideration the highest possible homogamy $M$ given the marginal distributions (or, conversely, the minimally necessary heterogamy),

$$
M=\frac{N-\frac{\sum_{j}\left|N_{j .}-N_{. j}\right|}{2}}{N}
$$

it is then possible to calculate to what extent the available "homogamy potential" (i. e. the difference between the highest possible homogamy $M$ and the randomly expected homogamy $C$ ) is exhausted by the actually occurring homogamy (relative homogamy or net homogamy $R$ ):

$$
R=\frac{H-C}{M-C}
$$

Tracing these measures $-H, C, M$ (or $1-M)$ and $R$-over time (period and cohort) reveals the extent to which the changes in observed homogamy are a consequence of purely structural effects, and the extent to which there are additional changes in the inclination to form educationally homogamous partnerships that are not due to structural effects. Note that the described method focuses on how the rate of agreement between the educational levels of the partners in couples changed over time. A supplementary approach that is often followed in the literature would be to analyze how the strength of the association between the partners' educational levels changed in general, irrespective of whether the levels coincide or not. Log-linear models are often used for this type of analysis. We focus here on the first approach, because it more closely resembles the conceptual idea of educational homogeneity within partnerships. The second approach, aiming at the strength of association rather than the strength of agreement, would make more sense when (for example) analyzing intergenerational educational mobility.

\section{$4 \quad$ Empirical results}

\subsection{Educational expansion in Switzerland in the second half of the 20th century}

First, we briefly present results on the extent of the educational expansion in Switzerland. Figure 1 shows the distribution of an educational variable reduced to three categories (high: tertiary education, medium: post-compulsory secondary education, low: compulsory schooling or less) by gender, five-year age groups and 
Figure $1 \quad$ Educational distribution by gender, age and year
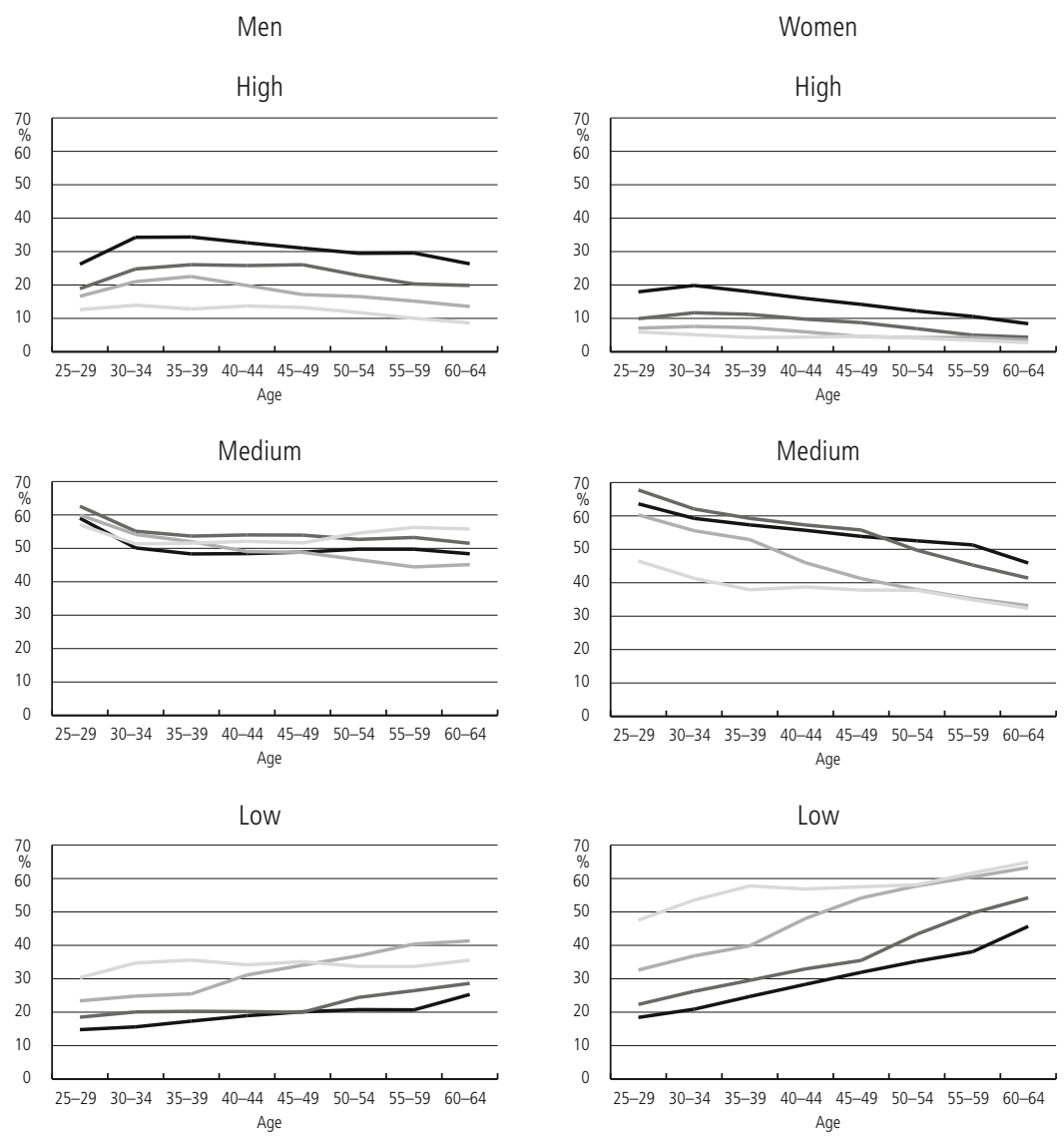

\begin{tabular}{|ll|}
\hline $1970 \quad 1980$ & -2000 \\
\hline
\end{tabular}

survey year. Changes over time become evident by a vertical comparison of the displayed curves. For example, in 1970, 14 percent of 30-34-year-old men had a tertiary education. In 2000, this share had risen to 34 percent. Over all age groups, there was an expansion of tertiary education for men from slightly more than 10 percent to about 30 percent. Similarly, there was also a significant increase in tertiary education for women, although the rise started later and was concentrated more among the younger age groups. 
At the other end of the educational scale, the share of people without postcompulsory education (compulsory schooling or less) declined significantly for both men and women. No clear trends are discernible for men in the medium educational category, while the share of women of medium education increased significantly, particularly between 1970 and 1990 .

In sum, the changes for men can be described as follows: strong expansion of the share of tertiary education coupled with a strong decline of those without post-compulsory education in all age groups during the entire period. For women, there was a strong expansion of upper secondary certificates and a simultaneous decline in the number of women without post-compulsory education across all age groups, mostly between 1970 and 1990, and a somewhat delayed expansion of tertiary education after 1980, particularly among younger age groups.

\subsection{Changes in partnership and educational homogamy}

How has the likelihood changed of having a partner with a similar educational background? As can be seen in Figure 2, the rate of partnerlessness has increased notably for men over time in all age groups (for example, men aged 40-44 years show an increase in partnerlessness from 16.9 percent in 1970 to 23.6 percent in 2000). In part this might be an artifact of a greater under-reporting of household-internal partnerships in more recent years, due to the pluralization of the household types. More plausible, however, is the interpretation that household-internal partnerships have indeed declined substantially. The reason might be that there has been an overall decline in the ratio of partnership bonds over time (at least partially because of increased divorce rates). Another possible reason could be that relationships have shifted toward partnerships across households ("living apart together"), perhaps because of tax advantages. Both phenomena probably contribute to the decrease in partnerships observed in the census data.

An increase in partnerlessness over the decades can also be observed for women, although only among younger age groups, as older women experienced a simultaneous decline in widowhood (see Figure A1 in the Appendix). Because of the relative increase of the life expectancy for men, one can even see a net decline in partnerlessness among women aged around 60 between 1970 and 2000.

Concerning educational homogamy, Figure 2 shows that partnerships in which the man has a higher educational level than the woman (hypergamy) declined noticeably due to the educational expansion, at least in the younger age groups (as evident in the topmost subgraph for men and in the third subgraph for women). ${ }^{9}$

9 Observations for which the homogamy variable is undetermined (due to lack of information on educational attainment for at least one of the partners; see Table A1 in the Appendix) have been excluded from the results in Figure 2. Excluding these observations reduces the number of people with a partner in the data, and thus inflates the proportion of partnerless people. To avoid such a bias and preserve the proportion of partnerless people at its true level, we proportionally rescaled the results from the homogamy variable. The correction is based on the assumption that 
Figure $2 \quad$ Educational homogamy and partnerlessness (living without a partner in the same household) by gender, age, and year

Men

Higher than partner

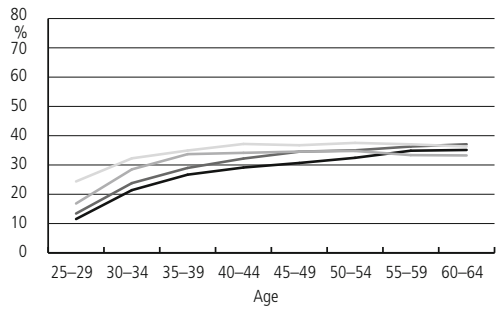

Same as partner

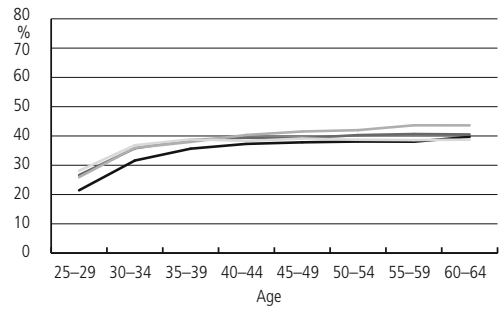

Lower than partner

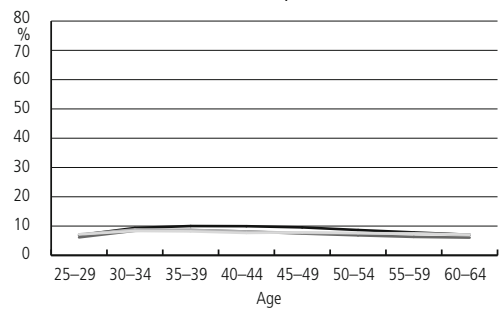

No partner

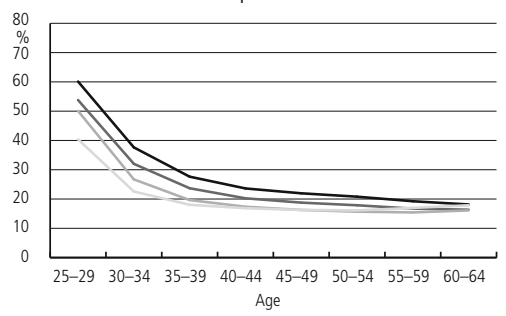

Women

Higher than partner

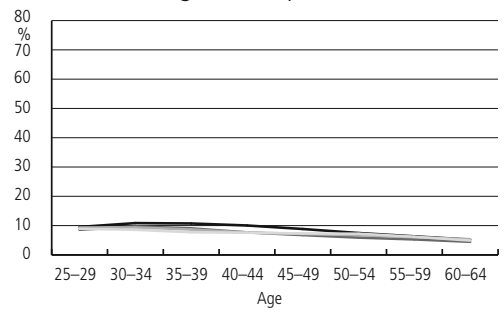

Same as partner

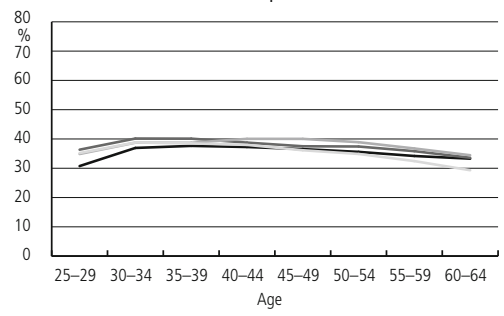

Lower than partner

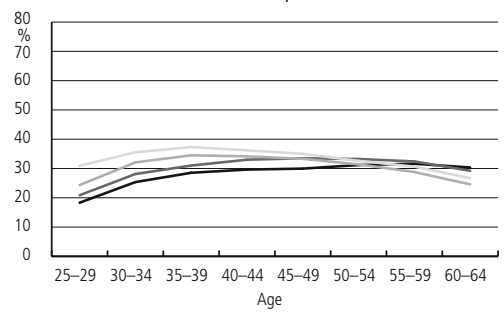

No partner

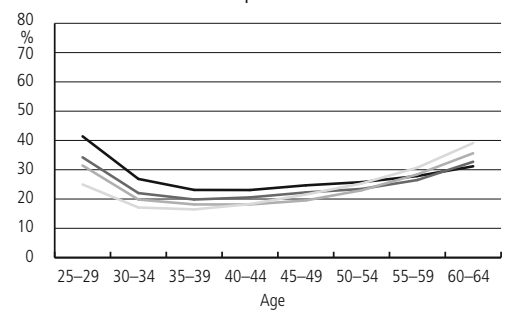

\begin{tabular}{|ll|}
\hline $1970 \quad 1980 \quad-2000$ \\
$-1990 \quad-2$
\end{tabular}


By contrast, partnerships in which the woman has a higher educational level than the man (hypogamy) increased slightly (which can, however, barely be seen in the diagrams, because the frequency of such configurations is still low). The number of couples in a relationship of educational homogamy also increased slightly between 1970 and 1980. However, a reversal of the trend is discernible between 1980 and 2000. In 2000, as a result, a slightly smaller share of persons is in an educationally homogamous partnership than was the case in 1970, at least in the younger age groups.

Overall, the changes in homogamy, hypergamy, and hypogamy during the 30-year period are moderate. Larger shifts, however, are disclosed when examining the rates by educational level (Figures 3, 4, and 5).

Figure 3 shows the changes for persons of a high educational level (tertiary education). While in 1970 approximately 80 percent of the highly educated middleaged men were in a hypergamous partnership, this share declined by the year 2000 to approximately 60 percent. In turn, the share of highly educated middle-aged men in an educationally homogamous partnership increased from about 10 percent to 20 percent. This is a direct consequence of the expansion of the number of women educated at a higher level. In other words, as a result of the equalization of the educational distributions, fewer men were forced to "marry down" in 2000 than was the case in 1970 .

Furthermore, across all age groups, there is also a noticeable increase in partnerlessness for highly educated men. For highly educated women, the trends are less clear. The proportion of highly educated women with a less educated partner always ranged between 20 and 30 percent in all age-groups. That is, like men, a substantial share of highly educated women had partners with less education, but at the same time the share of highly educated women in an educationally homogamous partnership increased significantly, primarily between 1970 and 1980 . The most striking result, however, is the relatively large share of highly educated women without a partner. In the middle-aged groups, this share amounts to about 30 to 40 percent. This phenomenon is likely due to the persisting traditional division of family roles and the unsatisfactory compatibility between family and work, which may make it unattractive for highly educated women to form or maintain a permanent partnership (see Imdorf and Hupka-Brunner 2015; Levy 2013). It should be noted, however, that this kind of partnerlessness has receded slightly over the years, except for the youngest age groups.

Men of a medium educational level (Figure 4) have similar trends to men of a high educational level. While in 1970 approximately half of the middle-aged men of a medium educational level lived in a hypergamous partnership, this share

the excluded observations are uninformative (missing at random). That is, we assume that the distribution of the homogamy variable is the same between the excluded observations and the observations for which we have complete data. 
Figure $3 \quad$ Educational homogamy and partnerlessness (living without a partner in the same household) for persons of high educational attainment by gender, age and year

Men

Higher than partner

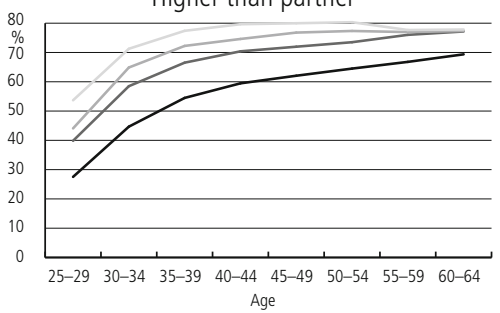

Same as partner

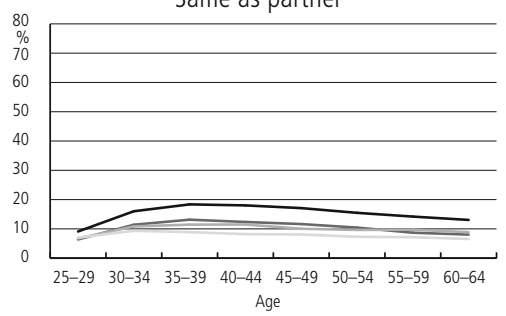

Lower than partner

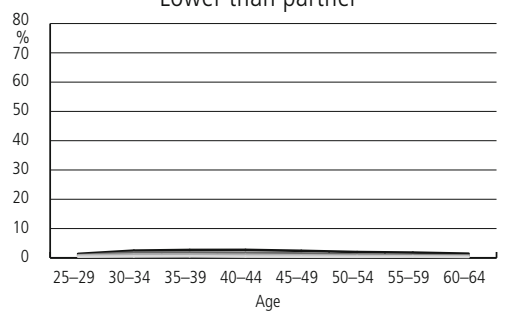

No partner

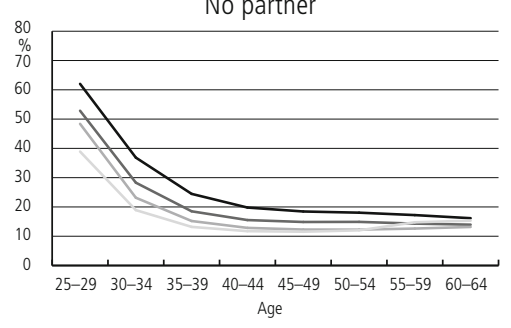

Women

Higher than partner

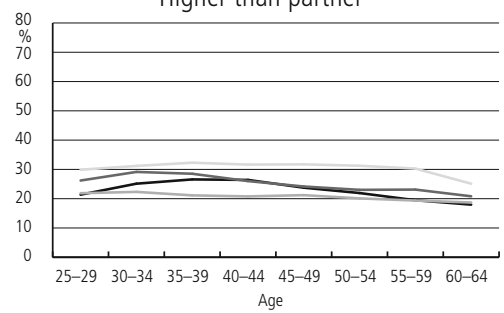

Same as partner

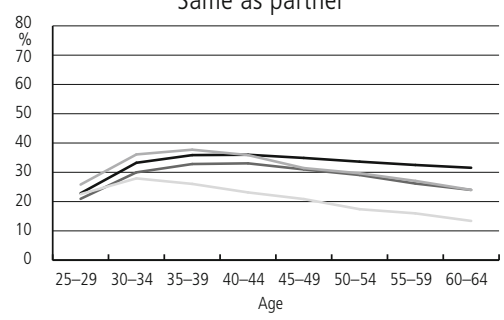

Lower than partner

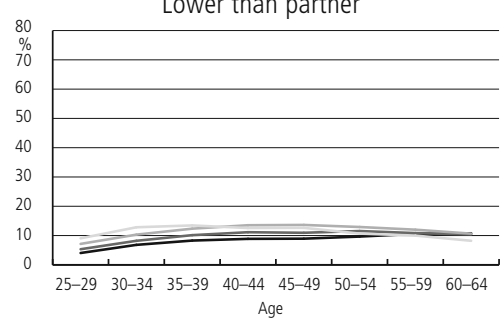

No partner

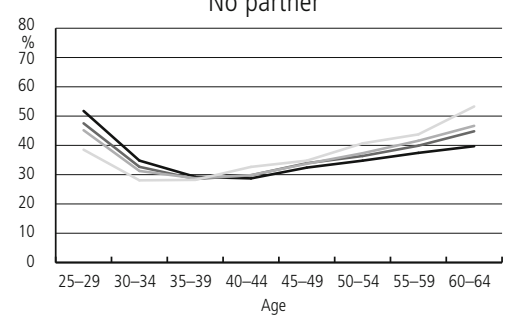


Figure $4 \quad$ Educational homogamy and partnerlessness (living without a partner in the same household) for persons of intermediate educational attainment by gender, age and year

Men

Higher than partner

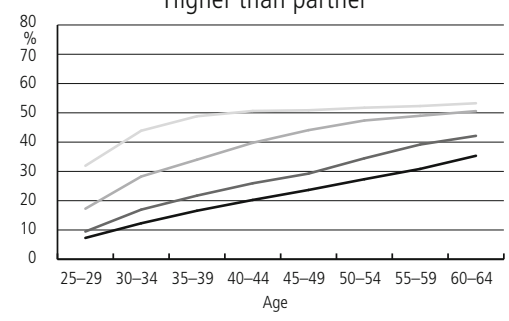

Same as partner

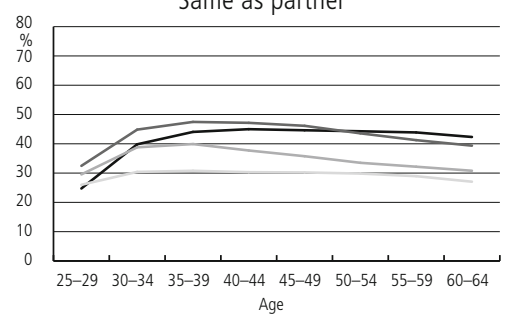

Lower than partner

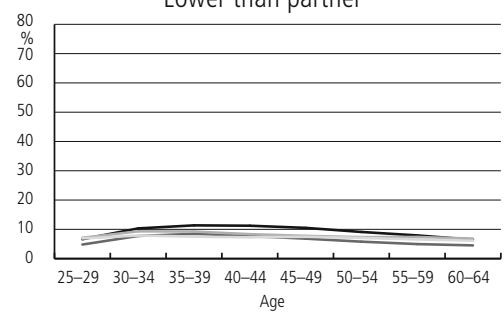

No partner

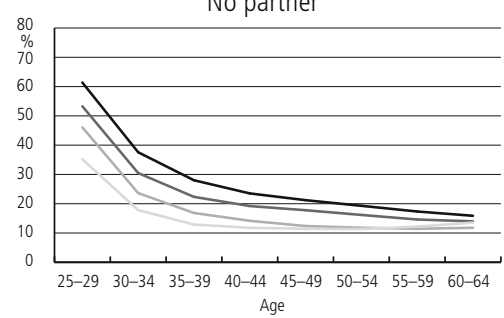

Women

Higher than partner

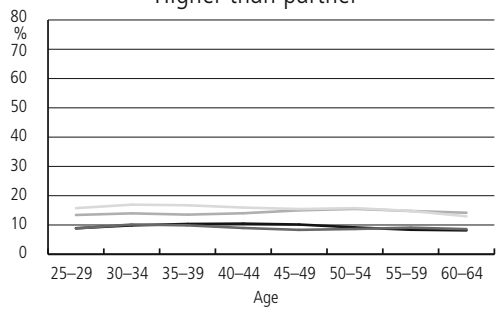

Same as partner

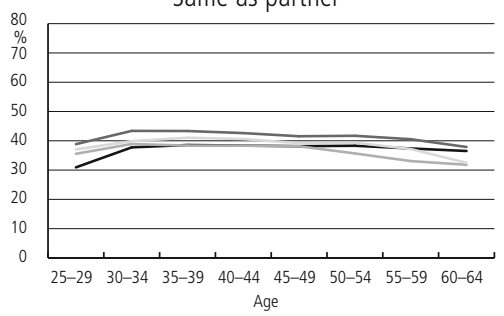

Lower than partner

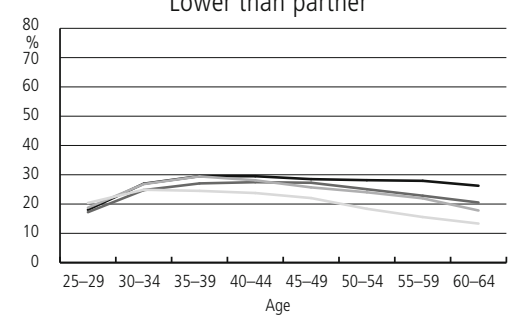

No partner

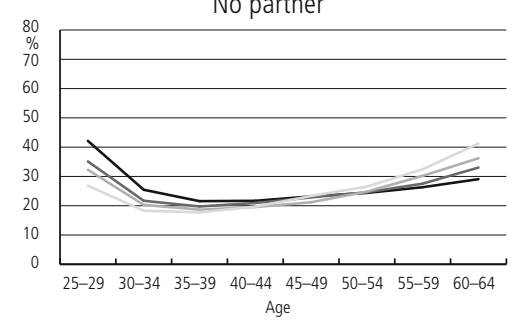

2000 
Figure $5 \quad$ Educational homogamy and partnerlessness (living without a partner in the same household) for persons of low educational attainment by gender, age and year

Men

Higher than partner

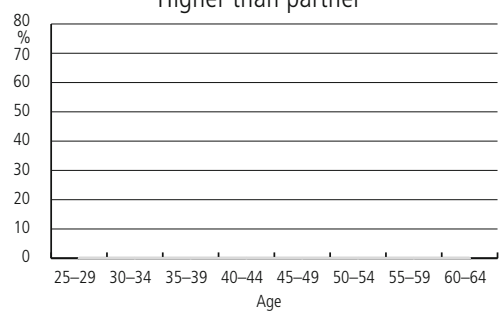

Same as partner

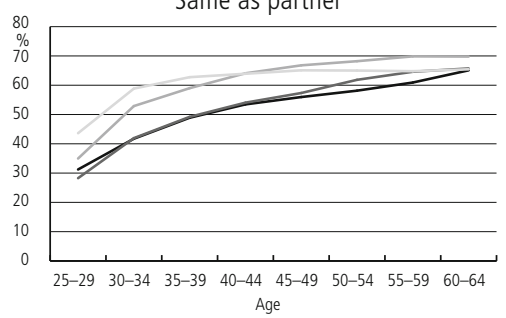

Lower than partner

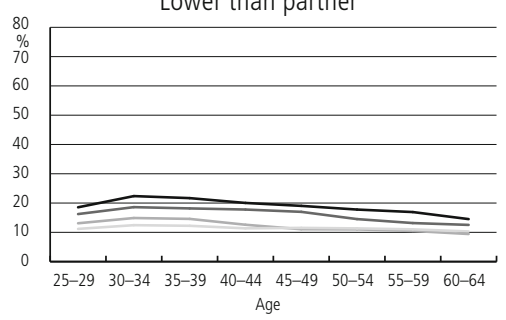

No partner

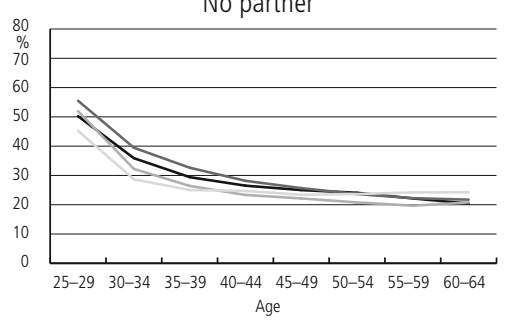

Women

Higher than partner

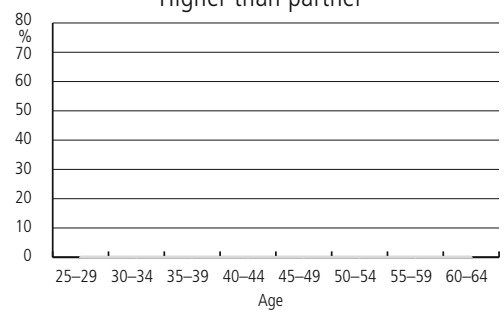

Same as partner

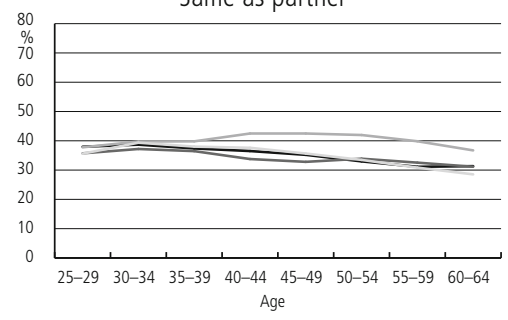

Lower than partner

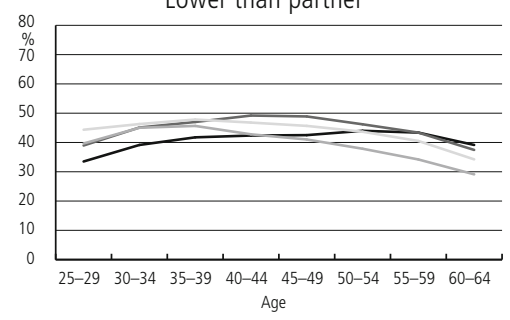

No partner

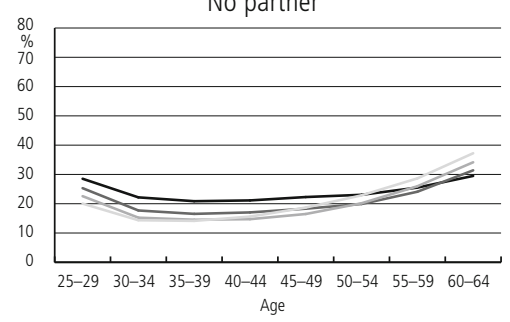

2000 
dropped dramatically to between 10 and 30 percent in 2000. By contrast, except for the youngest age group, the share of men of medium education living in an educationally homogamous partnership increased from 30 percent to approximately 45 percent. Furthermore, we also see a slight increase in hypogamous partnerships, and (much more pronounced) in partnerlessness (in the middle-aged groups, this share increased from a little over 10 percent to more than 20 percent). A more mixed picture emerges for women of a medium educational level. The share of these women who lived in a homogamous relationship remained relatively stable (approximately 40 percent), while relationships with a less educated partner trended down, and relationships with a more educated partner trended up. Partnerlessness among women of a medium educational level was significantly lower than among highly educated women, although there has been a slight convergence over time.

Finally, Figure 5 displays the changes for persons of low education. Educational homogamy among men in this group has declined substantially in the course of educational expansion (in middle-aged groups, from almost 65 percent to approximately 55 percent), while the share of men in a relationship with a more educated woman increased accordingly. Partnerlessness increased much less among men of low education than among men with a high or medium education. Except for the youngest age groups, however, partnerlessness is still most pronounced among men of a low educational level.

Interesting in this context is the comparison with women. While there is a negative relationship between educational level and partnerlessness among men, the situation for women is exactly the opposite. For both genders, however, the relationship has weakened over time, so that overall one can speak of a certain convergence. For example, a significant increase in partnerlessness can be observed for most age groups of women of a low educational level, who in 1970 were least affected by partnerlessness.

\subsection{Structural effects of the educational expansion}

We now turn to the question regarding the extent to which the observed changes in educational homogamy are due to purely structural effects as a result of the educational expansion. Partnerless persons are omitted from the analysis: that is, only persons who were in a relationship at the time of the census are considered as potential partners (i. e., it is assumed that partnerless persons are not available for the partner market). This assumption is made for methodical reasons, to be able to determine the relevant marginal distributions. Although it is possible that changes in education-specific mating behavior have effects on the pool of potential partners, it is unclear how such effects could be incorporated into the analysis. In essence, a sophisticated dynamic partner choice model would be required that distinguishes between partnerlessness due to lack of a potential partner with a desired educational level and partnerlessness due to other reasons. Developing such a model would 
exceed the scope of the current article; nor do we see how such a model could be implemented based on census data. As such, however, we do not expect the results from a more refined analysis to be fundamentally different from the results presented below, because partnerlessness can have many reasons and only some of them will be related to the dynamics of education-specific mating.

Figure 6 shows the development of gross (observed) homogamy, random homogamy, minimum heterogamy and net (relative) homogamy (see the definition of these quantities in Section 3) for women and men of different ages over time. The results are almost identical for women and men due to the symmetry of affairs: differences only come about because women and men do not only form partnerships with people of approximately the same age.

As we have already seen, the observed homogamy has not changed much overall. About half of all partnerships in all age groups are educationally homogamous (see the topmost subgraphs). From 1970 to 1980 or 1990, observed homogamy slightly increased, after which we again see a slight reduction. It can also be observed that the homogamy that would be expected under random matching declined somewhat due to a shift in the marginal distributions of the educational levels for women and men during the educational expansion, particularly between 1990 and 2000 (from about 35 percent to approximately 30 percent). This means that, based on purely structural changes in the educational distributions, somewhat fewer educationally homogamous couples could be expected in 2000 than in 1990.

The minimum necessary heterogamy given the marginal distributions - that is, the share of couples with a heterogeneous education that remains if one forms as many homogeneous couples as possible - has also declined over the entire period. Since the educational distributions of men and women have become similar over time, it has become ever easier for as many people as possible to find a partner with the same educational level. Since these two structural effects partially offset each other (fewer homogeneous couples in case of random matching, coupled with a higher potential for homogeneous couples), the net homogamy corrected for the structural effects shows a picture quite similar to that for the de facto observed gross homogamy. Between 1970 and 2000, there was no great change overall, or at best a marginal increase, in homogamy.

To provide a more differentiated picture, Figures 7, 8 and 9 again show results broken down by educational level. Overall, one can see an increase in the share of homogamous partnerships among men with high or medium education (see the topmost subgraphs in Figures 7 and 8) as well as among women with a higher level of education (see the topmost subgraph in Figure 7). For men of low education, educational homogamy has declined (see the topmost subgraph in Figure 9), while no clear trends are visible for women of a medium or low educational level (see the topmost subgraphs in Figures 8 and 9). 
Figure 6 Breakdown of educational homogamy by gender, age and year

Men

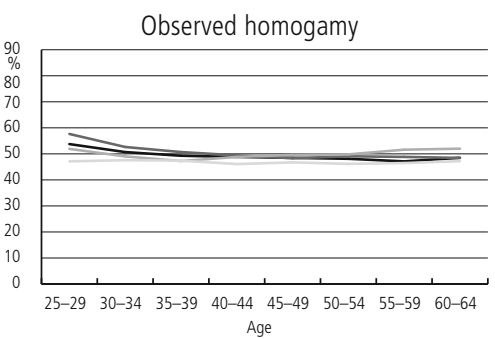

Chance homogamy

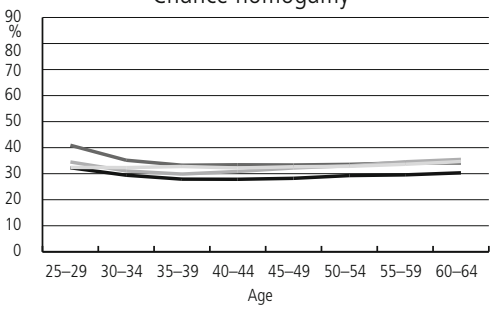

Minimal heterogamy

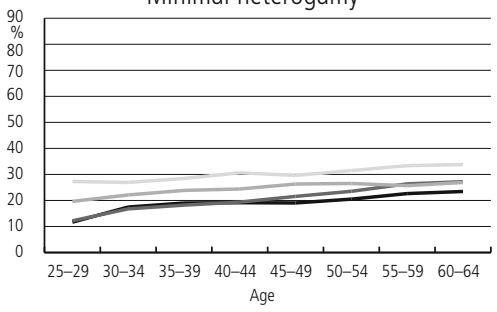

Relative homogamy

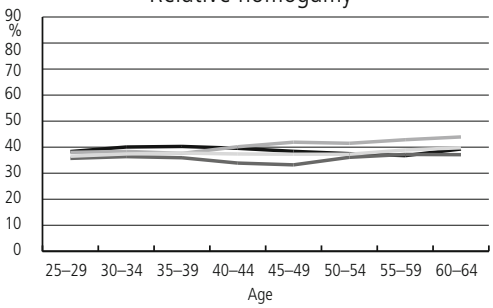

Women

Observed homogamy

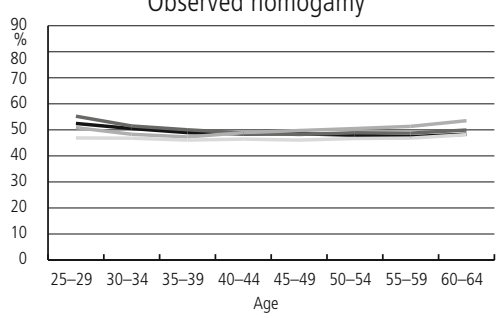

Chance homogamy

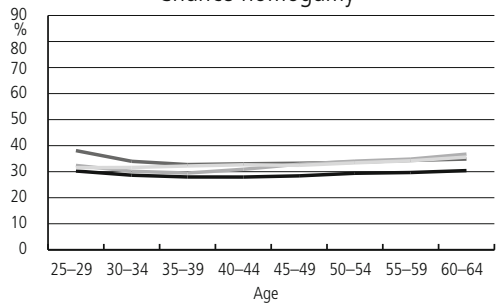

Minimal heterogamy

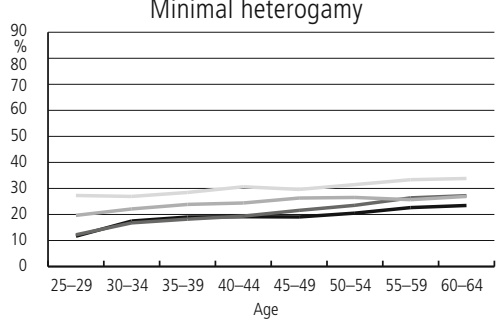

Relative homogamy

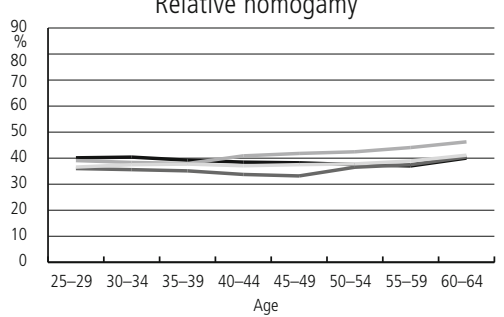


Figure $7 \quad$ Breakdown of educational homogamy for persons of high education by gender, age and year

Men

Observed homogamy

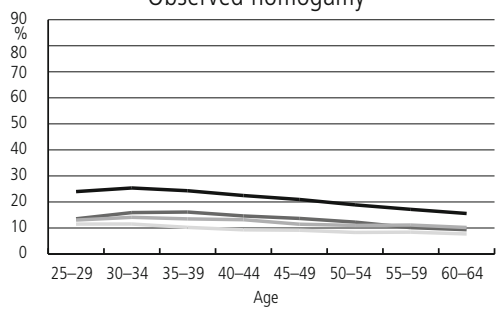

Chance homogamy

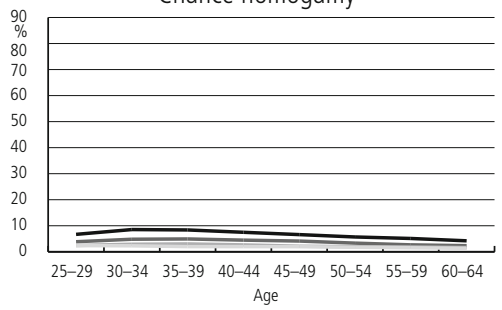

Minimal heterogamy

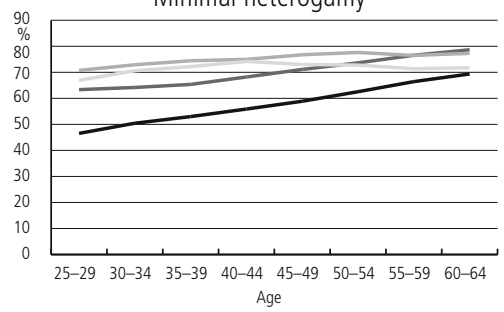

Relative homogamy

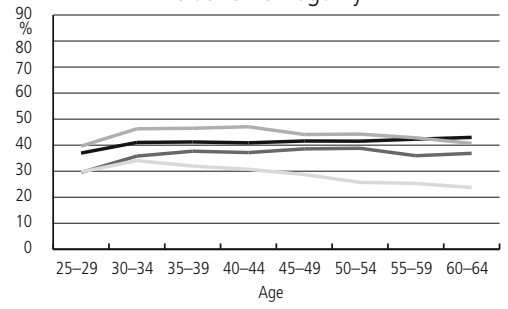

Women

Observed homogamy

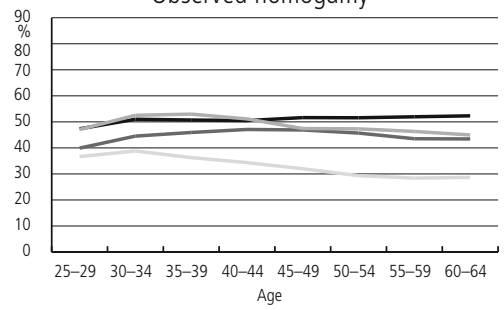

Chance homogamy

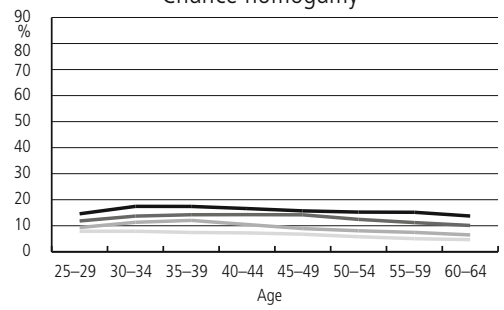

Minimal heterogamy

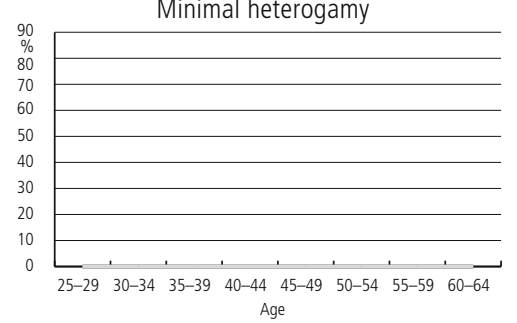

Relative homogamy

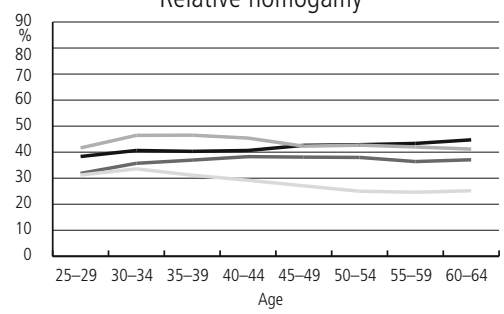

\begin{tabular}{|lll|}
\hline $1970 \quad 1980$ & $-1990 \quad 2000$ \\
\cline { 2 - 2 }
\end{tabular}


Figure 8 Breakdown of educational homogamy for persons of medium education by gender, age and year

Men

Observed homogamy

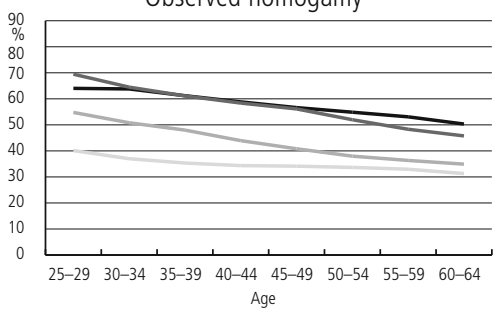

Chance homogamy

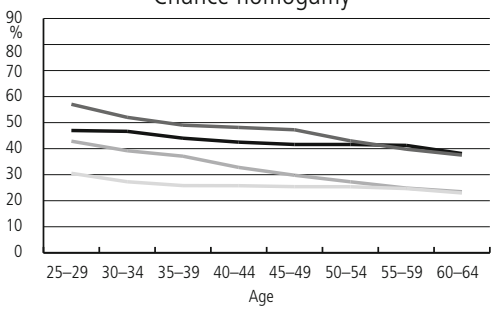

Minimal heterogamy

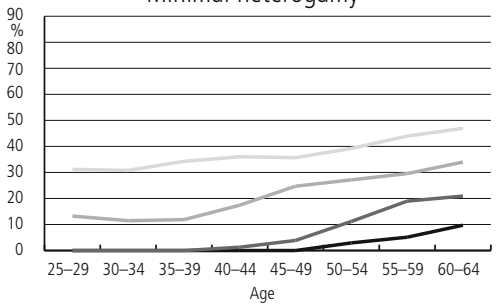

Relative homogamy

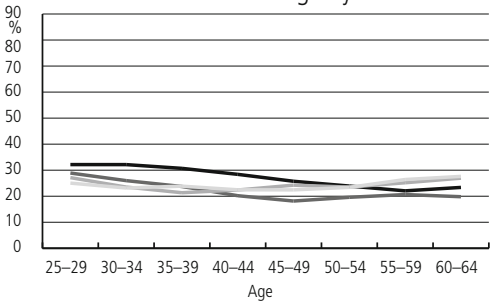

Women

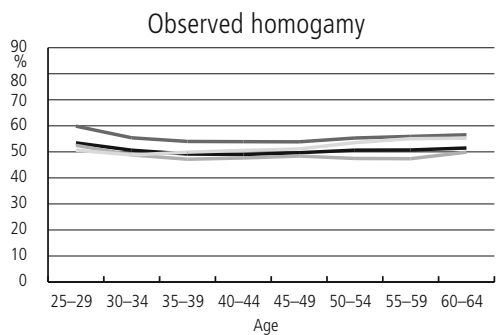

Chance homogamy

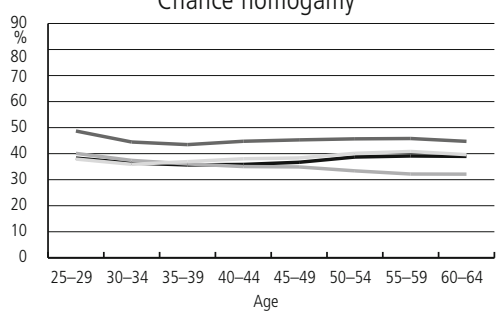

Minimal heterogamy

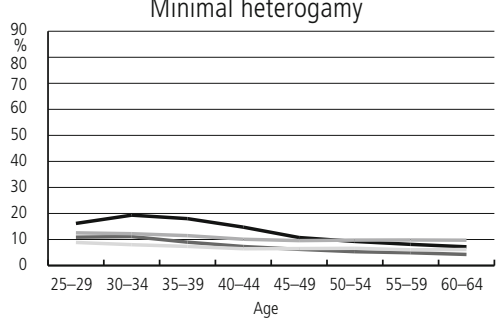

Relative homogamy

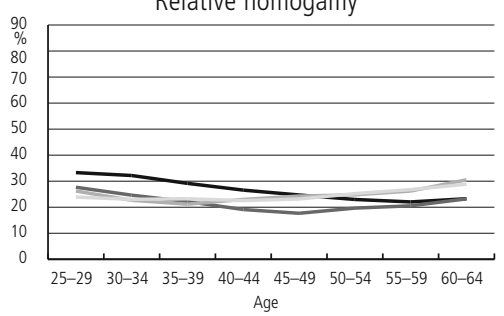

2000 
Figure 9 Breakdown of educational homogamy for persons of low education by gender, age and year

Men

Observed homogamy

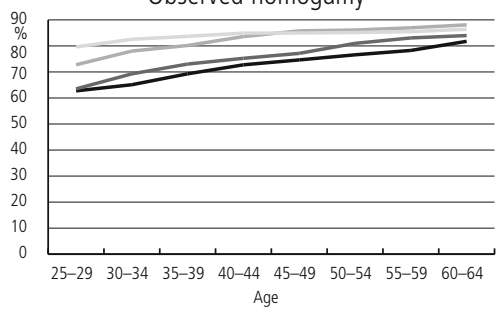

Chance homogamy

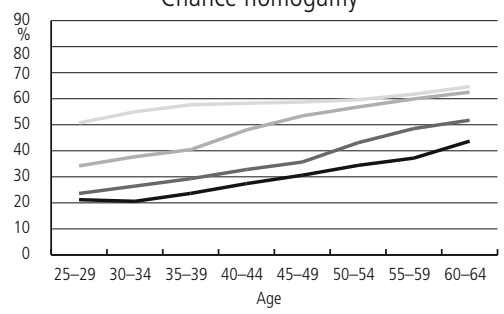

Minimal heterogamy

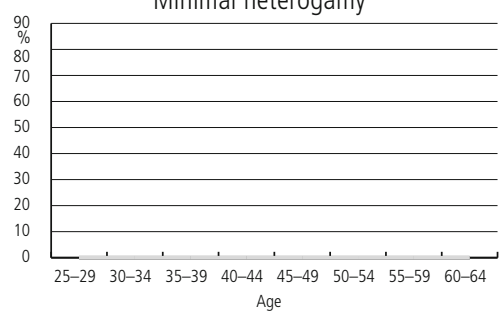

Relative homogamy

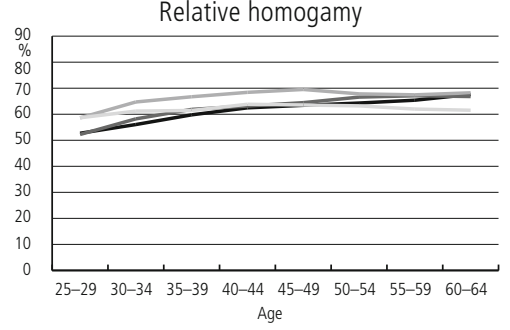

\begin{tabular}{|lll|}
\hline $1970 \quad 1980$ & $-1990 \quad 2000$ \\
\hline
\end{tabular}

Women

Observed homogamy

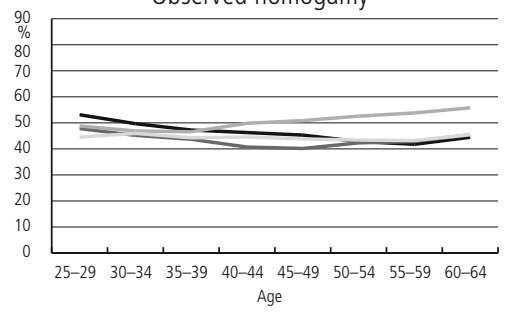

Chance homogamy

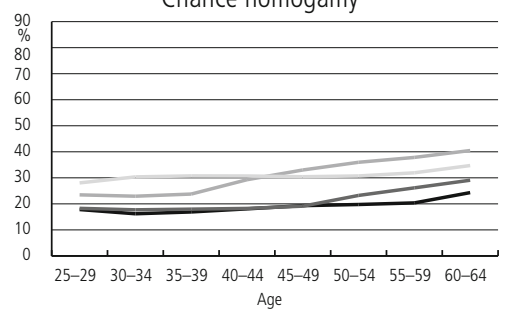

Minimal heterogamy

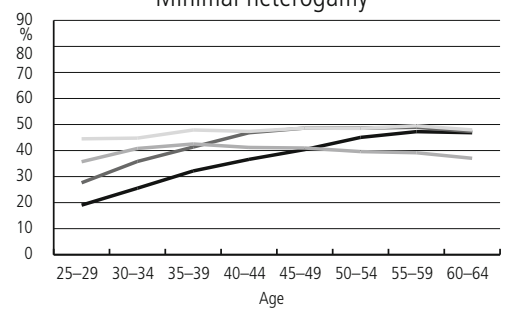

Relative homogamy

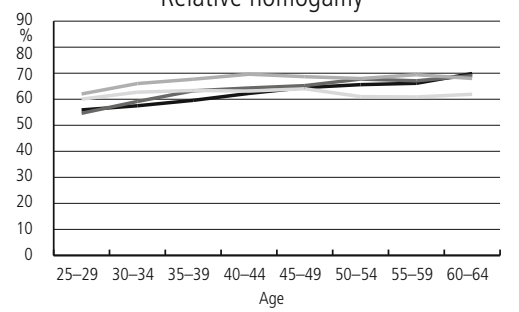
.

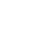


The observed changes seem largely due to structural effects. In the three cases in which an increase in educational homogamy occurred (men and women of high education; men of medium education), randomly expected homogamy has increased, and minimally necessary heterogamy has declined. That is, both structural effects were such that homogeneous partnerships became more likely. Accordingly, the trends in net homogamy, corrected for the structural effects, are substantially less pronounced than the trends in observed homogamy for these groups. ${ }^{10}$

For highly educated women and men, a substantial increase in the tendency towards homogamy can only be observed between 1970 and 1980 after taking the structural effects into account. After that, the situation has remained stable. Among men of medium education, there was a certain increase in the tendency towards homogamy in the younger age groups (mostly between 1990 and 2000), whereas for the older age groups relative homogamy somewhat declined (mostly between 1980 and 1990). Similarly, the decline of observed homogamy among men of low education was accompanied by a decline in randomly expected homogamy, so that here also only minor changes in net homogamy remained across the whole period.

In sum, it could be concluded that the observed changes in educational homogamy are due in large part to changes in the opportunity structures that are associated with a shift in the educational distributions in the course of educational expansion. No clear indication of a change in partner choice behavior can be found independently of structural effects in the data. Nonetheless, it is sociologically interesting to see that structurally adjusted partner choice behavior seems to differ between the educational groups. Net homogamy, which measures how much the observed homogamy exceeds what one would expect under random matching of partners, is highest for people of low education (about 60 percent). People of medium education reach the lowest values (20 to 30 percent). People of high education are located in between (around 40 percent). For persons of low education, the inclination to take their cue from their own group when choosing a partner thus seems highest, while it seems to be lowest among persons of medium education.

\section{Summary and discussion}

This article described the effects of the educational expansion on marriage markets and education-related partnership patterns for Switzerland in the second half of the $20^{\text {th }}$ century. The assumption was that the peculiarities of the comparatively moderate course of the educational expansion (Blossfeld and Shavit 1993), the slow changes in social structures and social inequality (Jann and Combet 2012), and the continuing traditional division of labor in private households (Levy 2013) in the face of the

10 That the values for net homogamy are nearly identical for men and women, despite some large differences in observed gross homogamy, is a logical consequence of the structural correction. 
increasing labor force participation of women (Imdorf and Hupka-Brunner 2015), all made Switzerland a special case in terms of the consequences of the educational expansion for demographic and family-demographic processes. It was therefore of special interest to examine, by means of census data for the total population, whether the upgrading across the birth cohorts resulted in a gradual social opening of the marriage and partnership markets and thus lead to a greater educational heterogamy of the couples, or whether traditional marriage patterns persisted, possibly coupled with an increase in homogamy among highly educated women and men and a greater disadvantage for persons of low education on the partnership market.

The census data allowed a step-by-step reconstruction of the theoretically assumed processes for the relation between educational expansion and partnership patterns for selected age groups. On the one hand, the empirical findings do not yield any clear trends in support of the social closure or opening of the partnership and marriage markets in Switzerland. In international comparison, Switzerland is a special case in this respect. On the other hand, interesting differential developments were uncovered. For example, partnerlessness (defined as not living with a partner in the same household) has increased among women and men of prime marriage age. This is particularly true for men of medium or high educational levels, whereas for women the effect can mostly be observed at lower educational levels, but not among the highly educated. Despite these trends, which lead to some convergence in the sex-specific educational gradients in partnerlessness, partnerlessness is still most prevalent among less educated men and more educated women. One potential reason is that men of a low educational level (and therefore a low average income) are particularly unattractive on the partnership and marriage markets, while highly educated women are less inclined to form steady relationships because their high economic and social independence is at odds with traditional family roles. However, note that, contrary to expectation, the negative relationship between partnerlessness and education for men and the positive relationship between partnerlessness and education for women have weakened over time. Furthermore, there are differential trends in homogamy depending on gender and on the educational level. Homogamy has increased substantially for highly educated women and men, as well as for men with a medium level education, whereas a noticeable decline in homogamy can be observed for men with a low level of education. Moreover, as expected due to the educational catch-up of women, hypergamy in men has declined in favor of hypogamy and homogamy. There are thus indications that women have profited more in this regard from the educational expansion than men. In these developments, Switzerland does follow the development patterns of other modern societies, albeit not as strongly as, for instance, in Germany.

If the structural effects of the educational expansion are taken into account, there was no noticeable change, or at best a marginally increased inclination toward homogamy across all educational levels between 1970 and 2000. The observed 
changes in educational homogamy therefore seem to be mostly due to changes in the opportunity structures associated with a shift of the educational distributions over the course of the educational expansion. However, the structurally adjusted partner choice behavior differs between the educational groups. Net homogamy is highest for less educated persons, and lowest for persons of medium education, while the highly educated are positioned between these two educational groups. The social closure is therefore highest for the groups that did not participate in the educational expansion, while the marriage market for the middle and higher educational groups is socially more open. In this sense one can talk of a polarized partner market, with a stronger closure at the lower end of the educational scale and a relative openness in the middle educational layers. The degree of polarization, however, slightly decreased over time, as there were moderate positive trends in net homogamy among the highly educated (primarily between 1970 and 1980) and among persons with a medium-level education (primarily between 1990 and 2000), whereas net homogamy remained rather stable for persons of low education.

One must assume that the norms of homogamy are still widespread and enshrined just as strongly in the Swiss social structure as the gender-typical division of labor in private households. Further analyses from the life course perspective, with event-oriented prospective panel data for successive age groups, are necessary to evaluate these issues empirically in more detail (see Blossfeld 2009; Blossfeld and Timm 2003;1997). For example, it is not possible to differentiate between a first marriage and remarriage based on census data. Additional analyses with up-to-date longitudinal data for Switzerland are necessary to determine whether the sustained educational expansion also promotes educational homogamy in cases when people remarry.

\section{References}

Arum, Richard, Josipa Roska, and Michelle J. Budig. 2008. The Romance of College Attendance: Higher Education Stratification and Mate Selection. Research in Social Stratification and Mobility 26(2): $107-121$.

Becker, Rolf. 2014. Reversal of Gender Differences in Educational Attainment - Historical Analysis of the West German Case. The Journal of Educational Research 56(2): 184-201.

Becker, Rolf. 2009. The Transmission of Educational Opportunities Across Three Generations - Prospects and Limits of the SOEP Data. Schmoller's Jahrbuch 129(2): 155-167.

Becker, Rolf, Franziska Jäpel, and Michael Beck. 2013. Geschlechterunterschiede im Bildungserfolg. Eine empirische Analyse für Schulkinder im Deutschschweizer Schulsystem unter besonderer Berücksichtigung ihres Migrationshintergrundes. Pp. 77-101 in Geschlecht, Migrationshintergrund und Bildungserfolg, edited by Andreas Hadjar and Sandra Hupka-Brunner. Weinheim: Juventa.

Becker, Rolf and Christoph Zangger. 2013. Die Bildungsexpansion in der Schweiz und ihre Folgen. Eine empirische Analyse des Wandels der Bildungsbeteiligung und -ungleichheiten mit den Daten 
der Schweizer Volkszählungen 1970, 1980, 1990 und 2000. Kölner Zeitschrift für Soziologie und Sozialpsychologie 65(3): 423-449.

Blau, Peter M. 1977. Inequality and Heterogeneity. New York: Free Press.

Blau, Peter M., Terry C. Blum, and Joseph E. Schwartz. 1982. Heterogeneity and Intermarriage. American Sociological Review 47(1): 45-62.

Blossfeld, Hans-Peter. 2009. Educational Assortative Marriage in Comparative Perspective. Annual Review of Sociology 35: 513-530.

Blossfeld, Hans-Peter and Andreas Timm. 2003. Educational Systems as Marriage Marktes in Modern Societies: a Conceptual Framwork. Pp. 1-18 in Who Marries Whom? Educational Systems as Marriage Markets in Modern Societies, edited by Hans-Peter Blossfeld and Andreas Timm. Dordrecht: Kluwer.

Blossfeld, Hans-Peter and Andreas Timm. 1997. Der Einfluss des Bildungssystems auf den Heiratsmarkt. Eine Längsschnittanalyse der Wahl des ersten Ehepartners im Lebenslauf. Kölner Zeitschrift für Soziologie und Sozialpsychologie 49: 440-476.

Blossfeld, Hans-Peter and Johannes Huinink. 1991. Human Capital Investments or Norms of Role Transition? How Women's Schooling and Career Affect the Process of Family Formation. American Journal of Sociology 97(1): 143-168.

Blossfeld, Hans-Peter and Yossi Shavit. 1993. Dauerhafte Ungleichheiten. Zur Veränderung des Einflusses der sozialen Herkunft auf die Bildungschancen in dreizehn industrialisierten Ländern. Zeitschrift für Pädagogik 39(1): 25-52.

Breen, Richard, Ruud Luijkx, Walter Müller, and Reinhard Pollak. 2010. Long-Term Trends in Educational Inequality in Europe: Class Inequalities and Gender Differences. European Sociological Review 26(1): 31-48.

Breen, Richard, Ruud Luijkx, Walter Müller, and Reinhard Pollak. 2009. Nonpersistent Inequality in Educational Attainment: Evidence From Eight European Countries. American Journal of Sociology 114(5): 1475-1152.

Buchmann, Marlis, Stefan Sacchi, Markus Lamprecht, and Hanspeter Stamm. 2007. Tertiary Education Expansion and Social Inequality in Switzerland. Pp. 321-348 in Stratification in Higher Education, edited by Yossi Shavit, Richard Arum, and Adam Gomoran. Stanford: Stanford University Press.

Chaze, Jean-Paul. 2005. Recensements fédéraux de la population 1970-2000. Harmonisation de la plus haute formation achevée. Laboratoire d'économie appliquée. Université de Genève.

Chaze, Jean-Paul, Marcel Bilger, and Caroline Schlesser. 2005. Les générations face au marché du travail: évolution de la vie active de 1970 à 2000. Neuchâtel: Office fédéral de la statistique (OFS).

Diekmann, Andreas. 1990. Der Einfluss schulischer Bildung und die Auswirkungen der Bildungsexpansion auf das Heiratsverhalten. Zeitschrift für Soziologie 19(4): 265-277.

Diekmann, Andreas and Kurt Schmidheiny. 2001. Bildung und Ehestabilität: Eine ereignisanalytische Untersuchung schweizerischer Familienbiografien. Swiss Journal of Sociology 27(2): 241-254.

DiPrete, Thomas A. and Claudia Buchmann. 2013. The Rise of Women. The Growing Gender Gap in Education and What It Means for American Schools. New York: Russell Sage Foundation.

Domanski, Henryk and Dariusz Przybysz. 2007. Educational Homogamy in 22 European Countries. European Societies 9(4): 495-526.

Falcon, Julie. 2016. Soziale Mobilität in der Schweiz im 20. Jahrhundert: zwischen Demokratisierung der Bildung und Fortbestand der Klassenungleichheiten. Social Change in Switzerland, http:// socialchangeswitzerland.ch (14.02.2017).

Hadjar, Andreas and Joel Berger. 2010. Dauerhafte Bildungsungleichheiten in Westdeutschland, Ostdeutschland und der Schweiz: Eine Kohortenbetrachtung der Ungleichheitsdimensionen soziale Herkunft und Geschlecht. Zeitschrift für Soziologie 39(3): 182-201. 
Hadjar, Andreas and Rolf Becker. 2009. Educational Expansion: Expected and Unexpected Consequences. Pp. 9-23 in Expected and Unexpected Consequences of the Educational Expansion in Europe and the US, edited by Andreas Hadjar and Rolf Becker. Bern: Haupt.

Hillmert, Steffen. 2012. Familienstrukturen und soziale Bildungsreproduktion. Pp. 325-345 in Soziologische Bildungsforschung. Sonderheft 52 der Kölner Zeitschrift für Soziologie und Sozialpsychologie, edited by Rolf Becker and Heike Solga. Wiesbaden: VS Verlag für Sozialwissenschaften.

Huinink, Johannes. 2000. Bildung und Familienentwicklung im Lebensverlauf. Zeitschrift für Erziehungswissenschaft 3(2): 209-229.

Huinink, Johannes. 1995. Education, Work and Family Formation Patterns of Men. Pp. 247-262 in The New Role of Women. Family Formation in Modern Europe, edited by Hans-Peter Blossfeld. Boulder: Westview Press.

Imdorf, Christian and Sandra Hupka-Brunner. 2015. Gender Differences at Labor Market Entry in Switzerland. Pp. 260-279 in Gender, Education, and Employment: An International Comparison of School-to-Work Transitions, edited by Hans-Peter Blossfeld, Jan Skopek, Moris Triventi, and Sandra Buchholz. Cheltenham: Edward Elgar.

Jann, Ben and Benita Combet. 2012. Zur Entwicklung der intergenerationalen Mobilität in der Schweiz. Schweizerische Zeitschrift für Soziologie 38(2): 177-199.

Kalmijn, Matthijs. 1998. Intermarriage and Homogamy: Causes, Patterns, Trends. Annual Review of Sociology 24: 395-421.

Kalmijn, Matthijs. 1991. Shifting Boundaries: Trends in Religious and Educational Homogamy. American Sociological Review 56(6): 786-800.

Kalmijn, Matthijs and Henk Flap. 2001. Assortative Meeting and Mating: Unintended Consequences of Organized Settings for Partner Choices. Social Forces 79(4): 1289-1312.

Katrnak, Tomas, Peter Fucik, and Ruud Luijkx. 2012. The Relationship Between Educational Homogamy and Educational Mobility in 29 European Countries. International Sociology 27(4):551-573.

Klein, Thomas. 2000. Partnerwahl zwischen sozialstrukturellen Vorgaben und individueller Entscheidungsautonomie. Zeitschrift für Sozialisationsforschung und Erziehungssoziologie 20(3): 229-243.

Klein, Thomas and Johannes Kopp (eds.). 1999. Scheidungsursachen aus soziologischer Sicht. Würzburg: Ergon-Verlag.

Konietzka, Dirk and Michaela Kreyenfeld (eds.). 2014. Ein Leben ohne Kinder. Ausmass, Strukturen und Ursachen von Kinderlosigkeit. Wiesbaden: Springer + VS Verlag für Sozialwissenschaften.

Levy, René. 2013. Regulating Life Courses: National Regimes of Gendered Trajectories. Pp. 225-242 in Gendered Life Courses Between Standardization and Individualization. A European Approach Applied to Switzerland, edited by René Levy and Eric Widmer. Wien: Lit Verlag.

Lichter, Daniel T., Robert N. Anderson, and Mark D. Hayward. 1995. Marriage Markets and Marital Choice. Journal of Family Issues 16(4): 412-431.

Mare, Robert D. 1991. Five Decades of Educational Assortative Mating. American Sociological Review 56(1): 15-32.

Mayer, Karl-Ulrich. 1996. Lebensverläufe und gesellschaftlicher Wandel. Pp. 43-73 in Kritische Übergänge. Statuspassagen und sozialpolitische Institutionalisierung, edited by Johannes Behrens and Wolfgang Voges. Frankfurt am Main: Campus.

Mayer, Karl Ulrich and Hans-Peter Blossfeld. 1990. Die gesellschaftliche Konstruktion sozialer Ungleichheit im Lebensverlauf. Pp. 297-318 in Lebenslagen - Lebensläufe - Lebensstile, edited by Peter A. Berger and Stefan Hradil. Göttingen: Otto Schwartz \& Co.

Müller, Walter. 1998. Erwartete und unerwartete Folgen der Bildungsexpansion. Pp. 81-112 in Die Diagnosefähigkeit der Soziologie, edited by Jürgen Friedrichs, Rainer Lepsius, and Karl Ulrich Mayer. Opladen: Westdeutscher Verlag. 
Nielsen, Helena Skyt and Michael Svarer. 2009. Educational Homogamy. How Much is Opportunities? The Journal of Human Resources 44(4): 1066-1086.

Pfeffer, Fabian T. 2008. Persistent Inequality in Educational Attainment and Its Institutional Context. European Sociological Review 24(5): 543-565.

Schwartz, Christine R. 2013. Trends and Variation in Assortative Mating: Causes and Consequences. Annual Review of Sociology 39: 451-470.

Schwartz, Christine R. and Hongyun Han. 2014. The Reversal of the Gender Gap in Education and Trends in Marital Dissolution. American Sociological Review 79(4): 605-629.

Schwartz, Christine R. and Robert D. Mare. 2012. The Proximate Determinants of Educational Homogamy: The Effects of First Marriage, Marital Dissolution, Remarriage, and Educational Upgrading. Demography 49(2): 629-650.

Schwartz, Christine R. and Robert D. Mare. 2005. Trends in Educational Assortative Marriage From 1940 to 2003. Demography 42(4): 621-646.

Smits, Jeroen. 2003. Social Closure Among the Higher Educated: Trends in Educational Homogamy in 55 Countries. Social Science Research 32(2): 251-277.

Smits, Jeroen, Wout Ultee, and Jan Lammers. 1998. Educational Homogamy in 65 Countries: An Explanation of Differences in Openness Using Country-Level Explanatory Variables. American Sociological Review 63(2): 264-285.

Stamm, Hanspeter and Markus Lamprecht. 2005. Entwicklung der Sozialstruktur. Neuenburg: Bundesamt für Statistik.

Timm, Andreas. 2006. Die Veränderung des Heirats- und Fertilitätsverhaltens im Zuge der Bildungsexpansion. Eine Längsschnittanalyse für West- und Ostdeutschland. Pp. 277-309 in Die Bildungsexpansion. Erwartete und unerwartete Folgen, edited by Andreas Hadjar and Rolf Becker. Wiesbaden: VS Verlag für Sozialwissenschaften.

Ultee, Wout C. and Ruud Luijkx. 1990. Educational Heterogamy and Father-to-Son Occupational Mobility in 23 Industrial Nations: General Societal Openness or Compensatory Strategies of Reproduction? European Sociological Review 6(2): 125-149.

Wirth, Heike. 1996. Wer heiratet wen? Die Entwicklung der bildungsspezifischen Heiratsmuster in Westdeutschland. Zeitschrift für Soziologie 25(5): 371-394.

Zangger, Christoph and Rolf Becker. 2016. Die Bildungsexpansion in der Schweiz - eine Reanalyse unter besonderer Berücksichtigung geschlechtsspezifischer Bildungschancen. Schweizerische Zeitschrift für Soziologie 42(3): 429-441. 


\section{Appendix}

Table A1 Number of observations (population aged 25-64 years), by educational level and partnership status

\begin{tabular}{|c|c|c|c|c|c|c|c|c|}
\hline & $\begin{array}{r}1970 \\
\mathrm{~N}\end{array}$ & $\%$ & $\begin{array}{r}1980 \\
N\end{array}$ & $\%$ & $\begin{array}{r}1990 \\
N\end{array}$ & $\%$ & $\begin{array}{r}2000 \\
N\end{array}$ & $\%$ \\
\hline Total & 3025803 & 100.0 & 3201572 & 100.0 & 3681257 & 100.0 & 3951740 & 100.0 \\
\hline \multicolumn{9}{|l|}{ By education } \\
\hline Low educational level & 1311073 & 43.3 & 1208926 & 37.8 & 1026176 & 27.9 & 899079 & 22.8 \\
\hline Medium educational level & 1337846 & 44.2 & 1494846 & 46.7 & 2023358 & 55.0 & 1969286 & 49.8 \\
\hline High educational level & 242264 & 8.0 & 368445 & 11.5 & 586487 & 15.9 & 857688 & 21.7 \\
\hline Unknown educational level & 134620 & 4.4 & 129355 & 4.0 & 45236 & 1.2 & 225687 & 5.7 \\
\hline \multicolumn{9}{|l|}{ By partnership status } \\
\hline Living without a partner & 688340 & 22.7 & 753929 & 23.5 & 954749 & 25.9 & 1117053 & 28.3 \\
\hline \multicolumn{9}{|l|}{ Living with a partner } \\
\hline Homogamy determinable & 2213089 & 73.1 & 2341445 & 73.1 & 2684449 & 72.9 & 2651606 & 67.1 \\
\hline Homogamy undetermined & 124374 & 4.1 & 106198 & 3.3 & 42059 & 1.1 & 183081 & 4.6 \\
\hline
\end{tabular}


Figure A1 Cumulative distribution of partnership status (living with or without a partner in the same household) by gender, age, and year Men

Women

2000

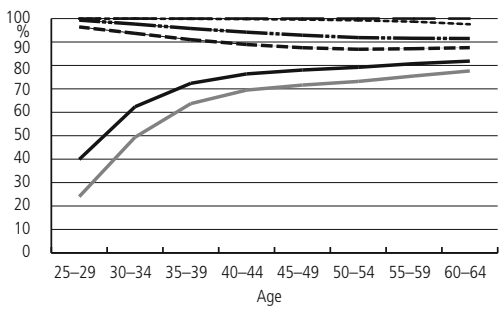

2000

1990

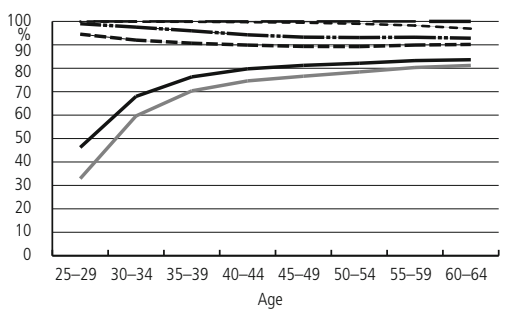

1980

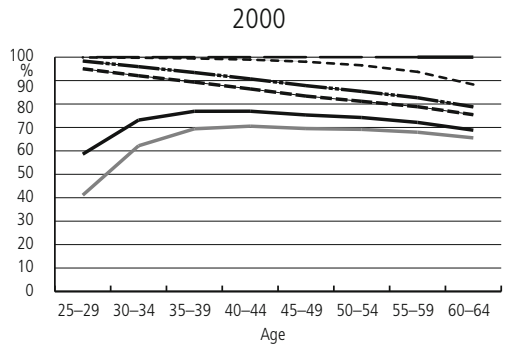

1990

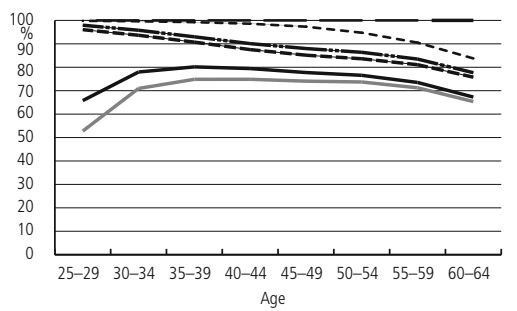

1980

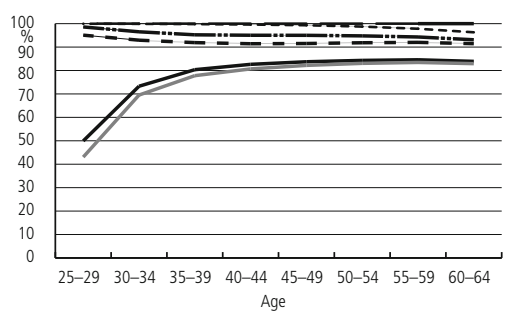

1970

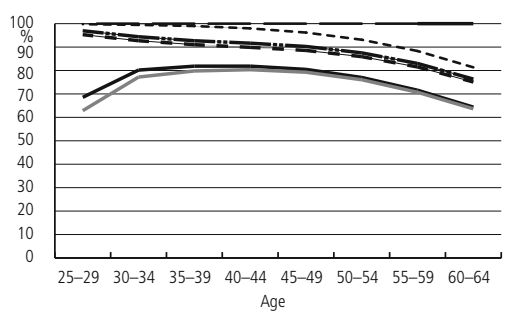

1970
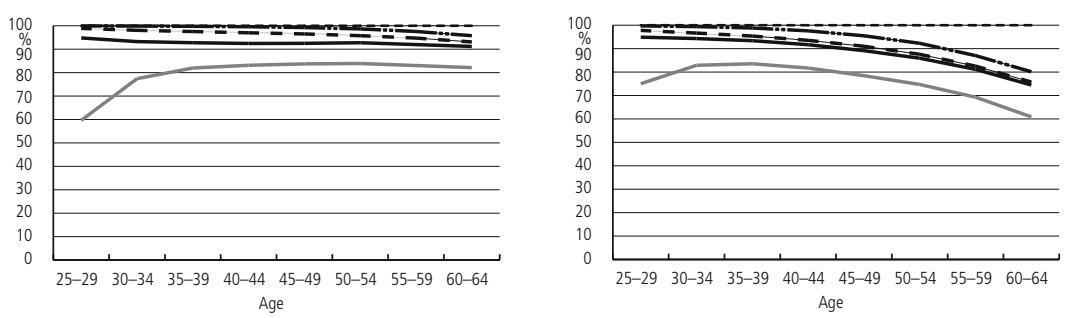
No partner
- widowed
divorced
-.-- separated
Partner
single consensual $\longrightarrow$ married 


\title{
Seismo Questions de genre Genderlssues
}

Delphine Gardey, Cynthia Kraus (dir./eds.)

\section{Politiques de coalition}

\author{
Penser et se mobiliser avec Judith Butler \\ Politics of Coalition \\ Thinking Collective Action with Judith Butler
}

Quelles sont les conditions de possibilité de l'agir politique et d'une démocratie radicale? Proposant une lecture empirique et théorique de l'œuvre de Judith Butler, ce livre discute l'actualité - parfois brûlante - des politiques de coalition dans différents contextes culturels. Bilingue, et rédigé par des auteures issues des quatre coins de l'Europe, il s'adresse à un large public intéressé par la pensée critique et les récents développements dans les études féministes, queer, postcoloniales et transnationales.

Avec un inédit de Judith Butler.

What are the conditions of possibility for political agency and a radical democracy? This book offers empirical and theoretical contributions engaging with Judith Butler's work and addressing the urgency of coalition politics in different cultural contexts. Written by researchers from all over Europe, the texts are available in French and English. The book is designed for a wide audience interested in critical thinking and the recent developments in feminist, queer, postcolo-

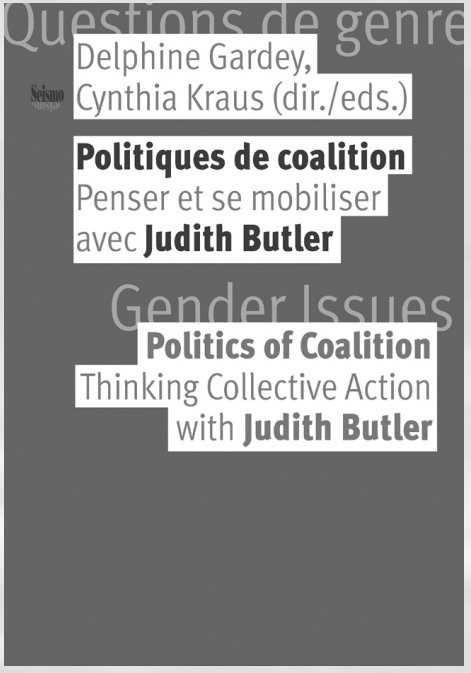

ISBN 978-2-88351-069-2, 284 pages, Fr. 44.- / Euro 39.nial and transnational studies.

Including an unpublished text by Judith Butler.

Delphine Gardey is a professor of contemporary history and director of the Institute of Gender Studies at the University of Geneva. She works on the history and sociology of the relations between gender, work, and technology, but also of bodies, gender and politics. Her recent book offers a material and gendered history of the French National Assembly.

Cynthia Kraus is a philosopher and a senior lecturer in gender studies and the social studies of science and medicine at the University of Lausanne. She works from an interdisciplinary perspective on the dynamics between laboratory research and clinical practice, professional and lay expertise, knowledge production and political action. 